\title{
Is it fun or exercise? The framing of physical activity biases subsequent snacking
}

\author{
Carolina O. C. Werle • Brian Wansink • \\ Collin R. Payne
}

Published online: 15 May 2014

(C) The Author(s) 2014. This article is published with open access at Springerlink.com

\begin{abstract}
Do consumers eat more when they exercise more? If so, the implications could ripple through the multi-billion dollar fitness and food industries and have implications for both consumers and health-care providers. Three studies - two field experiments and one observational field study - triangulate on this potential compensatory mechanism between physical activity and food intake. The findings showed that when physical activity was perceived as fun (e.g., when it is labeled as a scenic walk rather than an exercise walk), people subsequently consume less dessert at mealtime and consume fewer hedonic snacks. A final observational field study during a competitive race showed that the more fun people rated the race as being, the less likely they were to compensate with a hedonic snack afterwards. Engaging in a physical activity seems to trigger the search for reward when individuals perceive it as exercise but not when they perceive it as fun. Key implications for the fitness industry and for health-care professionals are detailed along with the simple advice to consumers to make certain they make their physical activity routine fun in order to avoid compensation.
\end{abstract}

Keywords Food consumption - Compensation · Physical activity · Licensing effects . Hedonic foods · Framing

When people begin exercise programs, they do not necessarily lose weight (Church et al. 2007). One reason may be because individuals reward themselves through

C. O. C. Werle $(\triangle)$

Grenoble Ecole de Management, 12, rue Pierre Sémard, BP 127, 38003 cedex 01 Grenoble, France

e-mail: carolina.werle@grenoble-em.com

B. Wansink

Cornell University, 110 Warren Hall, Ithaca, NY 14853-7801, USA

e-mail: Wansink@Cornell.edu

C. R. Payne

New Mexico State University, MSC 5280, PO Box 30001, Las Cruces, NM 88003-5280, USA

e-mail: crp@nmsu.edu 
compensation for physical excursion expended (King 1999; King et al. 1996; Martins et al. 2007) and overestimate calories burned relative to the calories consumed (Lichtman et al. 1992; Wansink and Chandon 2006). To understand how to attenuate this compensation, we examined how changing perceptions of physical activity through framing can impact subsequent food consumption.

The existence of such a potential compensation between two key recommendations for obesity prevention raises the question of how to correct it. Building on the delay of gratification theory (Mischel et al. 1989), we suggest that framing exercise as fun reduces individuals' tendency to indulge because it diverts their attention away from the effort required by the physical activity. Focusing attention on something else may change the perceptions of the effort expend during the activity, reducing feelings of entitlement due to exercising (Kivetz and Zheng 2006).

Our studies examine whether framing physical activity as fun can alter these compensation effects. This suggests a boundary condition of licensing effects: reducing the perceived effort (but not the real effort) in an exertion activity may change its effect on subsequent actions. We also examine if licensing effects of physical activity are selectively directed towards hedonic foods and not towards all kind of foods. This may suggest that weight gain due to compensation for physical activity is at least partly attributable to excessive consumption of hedonic foods that are often more caloric than utilitarian foods.

We begin with a brief review of relevant prior work on licensing effects and on the effects of distraction on delay of gratification. This leads to the prediction that labeling exercise as fun decreases subsequent compensation through food consumption. We present three studies that test this proposition in different settings and discuss theoretical and practical implications of this research.

\section{Theoretical framework}

Individuals tend to compensate previous efforts through hedonic consumption. For example, when exposed to a loyalty program requiring greater effort, individuals prefer a luxury reward in comparison to more utilitarian choices than when the program requires less effort (Kivetz and Simonson 2002). Similarly, donations to charity are preferred to a monetary incentive when they are bundled with a hedonic product such as a hot fudge sundae than when they are bundled with a utilitarian item (Strahilevitz and Myers 1998). Preference for luxuries, relative to utilities, is also enhanced by previous acts enhancing self-concept, such as donations to charity (Khan and Dhar 2006). Previous research on compensation between exercising and food consumption suggests that physical activity can have a similar licensing effect allowing individuals to increase subsequent energy intake (e.g., Martins et al. 2007). Indeed, mental effort (Chaput et al. 2008) and even imagined exercising may lead to increases in food consumption (Werle et al. 2011). In the same vein, exposure to messages promoting exercise also leads to increased food intake (Albarracin et al. 2009).

Research on justification effects demonstrates that prior decisions can serve as a license to choose indulgent options. It has been well documented that individuals tend to compensate previous efforts with hedonic choices (Kivetz and Simonson 2002; Kivetz and Zheng 2006; Mukhopadhyay and Johar 2009). When applied to the 
relationship between physical activity and food consumption, these findings suggest that compensation after exercising should be directed mainly towards hedonic foods (foods that are consumed mainly for pleasure or enjoyment motives) in comparison to utilitarian foods (consumed for practical or necessity motives).

If there is compensation between physical activity and food consumption, it is important to examine how to prevent it. Previous research demonstrated that altering perceptions of physical activity has positive perceptual and behavioral effects (Crum and Langer 2007). In an experiment with hotel room attendants, half of participants were told that cleaning rooms was considered as good exercise characterizing an active lifestyle, while half of them did not receive this information. Four weeks after the intervention, participants in the treatment condition perceived themselves to be getting significantly more exercise than before and had significant changes in health indicators, such as decreased body weight and blood pressure. These results suggest that simply changing the perception of an activity may have significant behavioral effects, but they only documented changes in participants' perception and in physical indicators (such as body weight, for example) with no direct behavioral measure. What has been largely unexplored is how changing the perception of a physical activity through framing may influence behavior and, specifically, food consumption.

Being distracted during an initial activity can alter perceptions of how it is experienced (Fillingim et al. 1989; Karageorghis and Terry 1997; Lerouge 2009; Nowlis and Shiv 2005; Shiv and Nowlis 2004). Previous research on delay of gratification among children shows that fun distractions enhance children's capacity to wait for a reward (Mischel et al. 1972). Distracting "fun" thoughts and selfgenerated activities helped to reduce child's frustration during the waiting period and increased delay time. When applied to exercise, activities such as listening to music can result in better tolerance to increased levels of training (Karageorghis and Terry 1997). According to the activity engagement theory (Higgins and Trope 1990), focusing on how enjoyable or fun an activity is may increase intrinsic motivation and positive affect increasing the drive for the activity. However, little is known about whether framing a physical activity as fun may impact subsequent food consumption. We propose that labeling an activity as fun may reduce the likelihood to compensate with food as a reward (Khan and Dhar 2006).

To understand how perceptions of physical activity influence food consumption, we conducted three studies. Studies 1 and 2 manipulated activity framing: participants performed a physical activity that was described either as fun or as exercise, and after which, food consumption was measured. In the first study, participants were allowed to freely consume hedonic and utilitarian foods in a buffet, and in the second, they served themselves a hedonic snack. Study 3 was a field observation study conducted during a race where participants were asked to rate how much fun they had while running and were offered the choice between two snacks (hedonic vs. utilitarian).

\subsection{Study 1: labeling exercise as fun reduces the consumption of hedonic sides in a meal}

Study 1 examined the effect of physical activity framing on the overall food consumption during a meal and, specifically, on the side options offered to participants. We predicted that participants would consume a greater amount of hedonic side options 
when their walking session is framed as exercise in comparison to when it is framed as fun.

Participants Fifty-six (56) female administrative staff members of a major Northeastern university (average age $=44.52$ years old) were recruited to participated in this study. Twenty-five participants (44.6 \%) had a normal body mass index (BMI). The study was conducted outdoors on the campus of a northeastern university (first phase) and in a university room that reproduces a real home kitchen and provides a natural environment for food consumption (second phase). Following IRB recommendations, participants were informed during recruitment that they would be engaging in an activity during the experience and should therefore wear comfortable shoes. The invitation also mentioned a free lunch after the experience.

Procedure At the beginning of the session, participants signed a consent form and were randomly assigned to a framing condition (exercise vs. fun). Those in the exercise condition were told that the purpose of the 30-min experience was to exercise (i.e., walking). They received a card with a map of a 1-mile walking route inside the university campus that they were to follow during the study. Six points of the route were highlighted on the map. At each, they were instructed to indicate their energy level.

In the fun condition, participants were told that the purpose of the 30-min walking experience was to do something fun. They were given the same 1-mile route as the exercise group, but instead were told that the purpose of the study was to listen to music through a MP3 player and to evaluate the clarity of the music at six different stopping points. They received a few instructions about how to operate the MP3 player, which contained the same selection of songs. Participants in both conditions were instructed to carry out the experience individually and were informed that after the activity, a lunch would be served.

After participants arrived from their walk, they received a short questionnaire to evaluate the activity and were told that lunch would be served soon. As a manipulation check, participants indicated their level of agreement with the sentence, "I found this activity exciting" on a 9-point Likert scale ( $1=$ not at all; $9=$ extremely). They were then asked to report their perception of the distance walked in miles and the number of calories they think they had burned during the activity. In order to examine the possible role of a goal progress mechanism (Fishbach and Dhar 2005), participants were also asked to indicate how effective they thought the activity was in making progress towards the goal of staying fit $(1=$ not at all; $9=$ extremely). Goal framework theories could argue that focusing on having fun or on exercising while performing a physical activity may actually impact the individuals' perception of progress towards high priority goals (i.e., staying fit or healthy; Fishbach and Dhar 2005). More specifically, the fact that participants in the exercise condition focused on the effort could have influenced their inferences in terms of goal progress and induced search for compensation.

Next, participants were individually invited to an all-you-can-eat buffet where they received instructions to serve themselves as much or as little as they wanted from different foods: pasta with meat, green beans, and bread. After that, they had the option to choose between two desserts - applesauce (utilitarian option) or chocolate pudding 
(hedonic option). They could take as much or as little dessert as they wanted, but they could only have one kind. We then took their trays and asked each participant to go to the corner of the room to choose a beverage, either regular Coke (hedonic option) or a bottle of water (utilitarian option). While they were choosing their drinks, we unobtrusively weighed their plates of pasta, green beans, bread, and dessert (separate plates for each). Participants received their trays back and were placed in an individual table to have lunch. During the meal, a TV show was presented on the lab television to discourage social interaction between participants. When participants finished their lunch, they answered a short questionnaire regarding their lunch experience. Then, they were thanked, debriefed individually, and allowed to exit. The entire experiment took 50-60 min. After participants left the room, research assistants weighed leftovers to estimate the actual amount of food consumed. Note that all measures were voluntary and therefore subject to participants' willingness to answer. Thus, some questions were left unanswered (as documented by the varying degrees of freedom in the analyses below).

Manipulation check and controls As expected, participants in the fun condition found the activity more exciting $(M=7.19)$ than those in the exercise condition, $(M=6.45$; $F(1,54)=2.83, p=.04$, one-tailed). The framing manipulation did not affect perceptions of the distance walked $(F(1,55)=.182 ; p=.671)$ nor did the perceived amount of calories burned during the activity $(F(1,52)=1.019, p=.32)$, suggesting that our effect is not attributable to different perceptions of physical effort across conditions (Kivetz and Simonson 2002). Results indicate no significant difference in perceptions of goal progress across conditions $(F(1,52)=2.05, p>.20)$, suggesting that the observed results cannot be explained by goal progress inferences (Fishbach and Dhar 2005).

Results An analysis of variance (ANOVA) was used to test the effect of framing (exercise $v s$. fun frame) on food consumption. Our dependent variables were the amount of food served and consumed by participants during the meal. We converted the weight measures of all the elements in the menu (green beans, pasta, bread, dessert, and drinks) into calories using the information available on the food manufacturers' websites. In the analyses, we initially entered participants' age, BMI, and level of hunger as potential covariates, but there were no effects and these variables are no longer discussed.

Interestingly, there were no statistical differences across conditions in the total amount of main course calories served $\left(M_{\text {fun }}=305.75, M_{\text {exercise }}=313.23, F(1\right.$, $55)=.180 ; p=.67)$ and consumed $\left(M_{\text {fun }}=258.07, M_{\text {exercise }}=271.87, F(1,55)=.392\right.$; $p=.53$ ). In contrast, the analysis of dessert and drink calories chosen indicates that participants in the fun condition served themselves fewer calories $\left(M_{\mathrm{fun}}=94.45\right)$ than participants in the exercise condition $\left(M_{\text {exercise }}=133.98, F(1,50)=2.791, p<.05\right.$, onetailed; see Table 1). These results indicate that compensation for physical effort was directed towards hedonic choices - in this case, chocolate pudding and regular soft drink - rather increasing aggregate calories.

It is noteworthy that there was no difference in the number of participants choosing hedonic sides across conditions: $50 \%$ of participants chose hedonic sides (either chocolate pudding as a dessert or a regular soft drink) in each condition $\left(\chi^{2}(1, N=\right.$ $32)=.000 ; p=.60)$. The difference in the number of calories across conditions is due to 
Table 1 Calories served in the meal and in hedonic side choices (study 1)

Number of calories

\begin{tabular}{llllll}
\hline $\begin{array}{l}\text { Total meal } \\
\text { served }\end{array}$ & $\begin{array}{l}\text { Regular meal* } \\
\text { (without sides) }\end{array}$ & $\begin{array}{l}\text { Hedonic choices } \\
\text { (drink+dessert) }\end{array}$ & $\begin{array}{l}\text { Chocolate } \\
\text { pudding served }\end{array}$ & $\begin{array}{l}\text { Apple sauce } \\
\text { served }\end{array}$ & $\begin{array}{l}\text { Drink } \\
\text { chosen }\end{array}$ \\
\hline
\end{tabular}

\begin{tabular}{cllllll}
\hline \multicolumn{2}{l}{ Exercise framing } & & & & & \\
Mean & 313.23 & 193.67 & 133.98 & 135.30 & 75.14 & 33.10 \\
S.D. & 132.73 & 116.96 & 111.00 & 54.16 & 35.05 & 84.22 \\
\multicolumn{2}{c}{$n=28$} & $n=28$ & $n=28$ & $n=11$ & $n=16$ & $n=29$ \\
Fun framing & & & & & \\
Mean & 305.75 & 210.32 & 94.45 & 100.10 & 89.79 & 9.23 \\
S.D. & 109.41 & 99.07 & 35.48 & 37.56 & 38.53 & 47.06 \\
\multicolumn{2}{c}{$n=28$} & $n=24$ & $n=24$ & $n=13$ & $n=13$ & $n=26$ \\
& NS & NS & $p<.05$ & $p<.05$ & NS & NS \\
\hline
\end{tabular}

*The regular meal was composed of pasta with beef, green beans, and bread

the amount of hedonic dessert served: participants in the exercise condition who chose chocolate pudding as a dessert served themselves more than participants in the fun condition who made the same choice $\left(M_{\text {fun }}=100.10, M_{\text {exercise }}=135.30, F(1,19)=5.011\right.$, $p<.05$, one-tailed). Similarly, participants in the exercise condition consumed more chocolate pudding than those in the fun condition $\left(M_{\text {fun }}=92.72, M_{\text {exercise }}=118.30, F(1\right.$, 19) $=4.763, p<.05$, one-tailed).

Next, an ANOVA tested the effect of framing on fatigue and on mood. Consistent with our hypothesis, the exercise condition resulted in participants reporting more fatigue after completing the walking experience than those in the fun condition $\left(M_{\text {fun }}=3.48, M_{\text {exercise }}=4.79, F(1,53)=7.698, p<.05\right)$. Additionally, individuals in the fun condition reported a more positive mood after completing the walking experience than those in the exercise condition $\left(M_{\text {fun }}=7.91, M_{\text {exercise }}=7.19, F(1,53)=7.698\right.$, $p<.01)$. These results suggest that focusing on having fun reduces perceptions of exertion associated with physical activity and increases positive mood.

Mediation analysis Next, we examined whether the effect of the framing manipulation on the number of calories of hedonic sides served was mediated by perceptions of fatigue or positive mood. A bootstrapping method (based on 1,000 bootstrap samples) was performed to examine indirect effects (Zhao et al. 2010) for each potential mediator. This analysis revealed that positive mood mediates the effect of the framing manipulation on the amount of calories of hedonic sides served: the mean indirect effect from the bootstrap analysis is negative and significant $(\beta=-12.79)$, with a $95 \%$ confidence interval excluding zero $(-32.829$ to -2.127$)$. The same analysis conducted for fatigue showed that this variable did not mediate the effects of framing on the number of calories of hedonic sides served ( $95 \% \mathrm{CI}=-28.650$ to 11.908).

Discussion Study 1 demonstrated that labeling a physical activity as fun can have positive consequences in terms of subsequent food decisions. Our results showed that when participants focused on exercising while walking, they felt more exertion 
(fatigue), they were in a less positive mood, and they consumed more of the hedonic sides offered during the meal. However, it is noteworthy that this overconsumption is not indiscriminate: there were no differences in the total number of calories consumed during the meal across conditions. The compensation in the exercise frame condition was directed towards hedonic side options only. Additional results showed that perceptions of effort, fatigue, or goal progress towards the objective of staying fit played no role in our findings. Furthermore, our results showed that the mechanism explaining these effects is the positive mood induced by the fun framing of the physical activity. Previous research in licensing effects demonstrated that more effortful activities lead to more hedonic choices (Kivetz and Simonson 2002; Khan and Dhar 2006). We contribute to this literature by showing that when an effortful activity is perceived as exercise, it leads to increased consumption of hedonic foods (but not of utilitarian foods) in comparison to when the same activity is perceived as fun. These results suggest that framing a physical activity as fun may be a way to diminish licensing effects.

\subsection{Study 2: labeling exercise as fun diminishes the amount of hedonic snacks served}

Study 1 provided preliminary evidence for the effect of physical activity framing on food consumption. However, our manipulation did not rule out any differential effects the mere presence of music in fun (vs. no music in the exercise) had on consumption. Specifically, it could be that the music in the fun condition was distracting, which could have increased positive mood independently of our fun framing. Therefore, although the manipulation check worked, it is not clear if our effects could be attributed to the presence versus absence of music or to the fun versus exercise framing manipulation. Study 2 addressed this issue by using a more ecologically valid manipulation of framing: participants performed the same walk as in study 1 but only the description of the walk changed across conditions. In the fun condition, the walk was described as a campus visit and participants were instructed to sightseeing while in the exercise condition, the walk was described as exercise. Furthermore, we also looked into a different dependent variable: the amount of hedonic snacks served. We predicted that participants would be more likely to serve themselves a greater amount of snacks when the physical activity was labeled as exercised than when it was labeled as fun.

Participants Forty-six administrative staff members of a major Northeastern university ( $87 \%$ women, average age $=44.35$ years old) participated in this study. Thirty-two of them $(69.6 \%)$ had a normal BMI. The study was conducted outdoors on the campus of the university. Participants were informed during recruitment that they would be engaging in an activity during the experience and should therefore wear comfortable shoes.

Procedure After reading and signing the consent form, participants were randomly assigned to one of the two conditions. Participants in the exercise condition received the same instructions as those in study 1 (i.e., walking through a 1-mile route to exercise). In the fun condition, participants followed the same walking route, but in this condition, the activity was described as sightseeing. After reading and signing the 
consent form, participants were told that the purpose of the 30-min experience was to do something fun: visiting the campus and sightseeing. Participants were given the same card as those in the exercise condition, but instead of rating their energy levels, they were told to observe and evaluate each of the six different points of the sightseeing route. In both conditions, participants followed the same walking route and were instructed to carry out the experience individually.

When participants finished their walk, as a thank-you for their participation, we offered them a sweet snack (M\&M's), which was to be poured into Ziploc bags. The M\&M's were presented in 1 gal-size serving bowls. All participants used the same size quarter-cup scoop to dish out the M\&M's. After pouring as much or as little as they wanted, a research assistant unobtrusively weighed the bags while participants answered a final set of questions. Then participants were debriefed individually and thanked.

Results A one-way analysis of variance (ANOVA) tested the effect of framing (fun vs. exercise) on the number of calories in the amount of M\&M's selected by participants. Again, we converted the weight measures of the M\&M's into calories using the manufacturer's information. BMI, gender, and age were included in the analysis but had no effect and are no longer discussed. As suggested, there was a significant main effect of the manipulated factor on the amount of M\&M's served, so that participants in the exercise condition took more $\mathrm{M} \& \mathrm{Ms}\left(M_{\text {exercise }}=372.3 \mathrm{cal}\right)$ than those in the fun sightseeing condition $\left(M_{\text {fun }}=166.2 \mathrm{cal} ; F(1,45)=5.06, p<.05\right)$.

Discussion In line with our theorizing and with the results of study 1, focusing on having fun while performing a physical activity reduced the amount of hedonic snack served. Participants in the exercise condition served themselves more hedonic snacks (M\&M's) than participants in the fun condition.

\subsection{Study 3: having fun during a race increases the choice of a healthy snack}

In this observational field study, we hypothesized that runners who perceived themselves as having fun during a race would be less likely to compensate from their physical exertion by choosing to eat a hedonic, less healthy snack after the race. Consistent with the first two studies, we predicted that if they had fun, they would not feel the need to reward themselves through food consumption.

Procedure This study was conducted during a real race: ekiden race, which is a marathon, ran in a relay of six runners completing distances of 5,10 , or $7.195 \mathrm{~km}$. We collected data at the finish aid station interviewing runners who finished their part of the race. When participants were leaving the station, they were invited to fill in a paper and pencil survey about their perception of the race. At the beginning of the questionnaire, the participants were told that to thank them for their participation, they would receive a snack and they could choose between a chocolate bar (relatively unhealthy food choice) and a cereal bar (relatively healthy food choice). They then answered a set of questions about their perception of the race (e.g., to what extent they had fun while running) and their individual characteristics (age, gender, height, weight). 
When participants handed in the filled questionnaire, the research assistant checked their choice and gave them the corresponding snack. The bars were put in envelopes to avoid having the brand influence the choice of the participants.

Participants Two hundred and thirty-one runners aged between 16 and 67 years old $(M=35.64 ; 65.1 \%$ male $)$ accepted to participate in this study. One hundred and eightytwo of them (79\%) had a normal BMI. One hundred and eighteen participants ran $5 \mathrm{~km}$ (50.4\%), 85 participants ran $10 \mathrm{~km}(36.6 \%)$, and 29 ran $7.195 \mathrm{~km}(12.5 \%)$.

Results Binomial logistic regression was used to test our predictions. The key dependent variable was snack choice, coded as one if a participant selected the relatively unhealthy snack choice (chocolate bar) and zero if a participant selected the relatively healthy snack choice (cereal bar). The extent to which participants had fun during the race was entered in the analysis as a continuous predictor variable. BMI and level of hunger were included as continuous predictor variables in the analysis, but their effect was not significant and these variables are no longer discussed. We also controlled for any effect of length of race $(5 \mathrm{k}, 7.2 \mathrm{k}$, or $10 \mathrm{k})$, but we found no effect. The main effect of having fun on snack choice was significant $\left(B=-.204, \chi^{2}(1)=3.694, p=.05\right)$ : participants who had more fun during the race were more inclined to choose the cereal bar than participants who had less fun.

Discussion Long-distance runners have a variety of ways they can frame their experience in a race. If competitive, they can view their race as a serious effort to win a medal or achieve a personal best time. Alternatively, some other runners could view the race as a form of a workout or exercise, but still others could see it as a form of adventure or as a "fun run." How they view their 30-60 min experience relates to what they chose to eat following the race. This is consistent with the findings of studies 1 and 2 and consistent with the rationale they offered.

\section{General discussion}

Although it has been established that previous efforts may lead to compensation (e.g., Kivetz and Simonson 2002), there has been limited evidence on how to prevent this compensation. The present research specifically focused on the relationship between physical activity and food consumption, two key recommendations to prevent obesity. Specifically, we looked into how framing physical activity as something fun may prevent compensation through food consumption.

Across three studies, in both lab and field settings, we found that framing a physical activity as fun (vs. exercise) influenced participants subsequent behavior. Specifically, we found that labeling a physical activity as fun reduced the amount of calories consumed in side dishes during a meal (study 1), the amount of hedonic food served (study 2), and perception of fun during a race positively influenced the choice of a healthy snack (study 3). In line with previous research (Martin et al. 2007), these effects were consistent after controlling for BMI.

This is, to our knowledge, the first demonstration of how framing a physical activity may differentially influence actual food consumption. Importantly, the findings of the 
field study (study 1) and the observational study (study 3) replicated previous work on licensing effects (e.g., Khan and Dhar 2006) showing that compensation for physical activity is primarily directed towards hedonic rather than utilitarian food products. In study 1, the effects of physical activity framing on the amount of calories in the hedonic sides served were mediated by positive mood, suggesting a hedonic mechanism behind these effects. It seems that participants were having enough fun during the walk to prevent them from compensating through extra hedonic food consumption. These results are in line with the activity engagement theory (Higgins and Trope 1990; Higgins et al. 1995), which suggests that there is no need to compensate for fun intrinsically motivating activities in comparison to work activities that are more extrinsically motivating and therefore highly associated with extrinsic rewards.

Future research should test other potential mechanisms behind the main effect documented here. For example, recent research (Laran and Janiszewski 2011) based on self-determination theory suggests that perceived vitality (Ryan and Deci 2008) could mediate the relationship between effort and food consumption. According to this research, because fun exercising is closely related to internal motivation, it should also enhance perceived vitality (i.e., people will feel more energized) and therefore reduce compensation through food consumption. This is an important area for future research.

Knowing that framing a physical activity as something fun reduces compensation through food consumption is important from a public policy standpoint. The implications of the effect of exercise framing on consumption not only resonate with, but also present a solution to, current public policy and health issues on weight and obesity. Specifically, strategic interventions drawn from our work that highlight the fun of physical activity can be designed with the knowledge that past research using behavioral manipulations and measuring food consumption had demonstrated promising results. Furthermore, the fact that our studies were based on real physical activities and actual consumption behaviors, rather than imagined scenarios and measuring preferences and attitudes regarding hedonic relative to utilitarian food, shows the ecological validity of our findings.

These results have significant relevance for the multi-billion dollar fitness and snack food industries. The profitability of fitness centers and gyms is not only related to how many members join but also to how long they stay involved and pay their monthly membership fees. Insofar as personal progress is likely to encourage one to maintain their membership, the fitness center or gym that warns or otherwise educates members to not compensate after their workout by overeating is likely enhancing the success of their members as well as their own revenue. Analogously, manufacturers of fitness equipment - treadmills, elliptical machines, and so on-should be similarly motivated to warn and encourage people not to compensate their new workout routines by overindulging with food as an after workout reward. Although the sales price of their machine may be a sunk cost, the more success and satisfaction people have with using it - and losing weight, if that is a goal - the better the word-of-mouth recommendations, loyalty, and future purchase potential will be.

Health-care practitioners that provide advice related to physical activity and weight - including physicians, dieticians, nurses, and so on - could be well advised to warn their patients and clients about the danger of energy compensation. This is especially important given that many recommendations involve both the encouragement to exercise more and to eat less. Without informing consumers that their initial 
tendency might be to exercise more and to also eat more, they could be setting these individuals up for disappointment or discouragement.

Lastly, consumers who are contemplating beginning a physical activity routine in order to help lose weight would be well advised to make certain they reframe it so they see it as fun - or at least not as work or exercise. Listening to music during a run, making phone calls during a walk, or watching a video during a treadmill routine may be more related to weight loss success and to perseverance than previously thought.

Acknowledgments We thank Olivier Corneille, Jannine Lasaleta, the editor, and the anonymous reviewers for their helpful comments.

Open Access This article is distributed under the terms of the Creative Commons Attribution License which permits any use, distribution, and reproduction in any medium, provided the original author(s) and the source are credited.

\section{References}

Albarracin, D., Wang, W., \& Leeper, J. (2009). Immediate increase in food intake following exercise messages. Obesity, 17, 1451-1452.

Chaput, J. P., Drapeau, V., Poirier, P., Teasdale, N., \& Tremblay, A. (2008). Glycemic instability and spontaneous energy intake: association with knowledge-based work. Psychosomatic Medicine, 70, 797-804.

Church, T. S., Earnest, C. P., Skinner, J. S., \& Blair, S. N. (2007). Effects of different doses of physical activity on cardiorespiratory fitness among sedentary, overweight or obese postmenopausal women with elevated blood pressure. Journal of the American Medical Association, 19, 2081-2091.

Crum, A. J., \& Langer, E. J. (2007). Mind-set matters: exercise and the placebo effect. Psychological Science, $18(2), 165-171$.

Fillingim, R. B., Roth, D. L., \& Haley, W. E. (1989). The effects of distraction on the perception of exerciseinduced symptoms. Journal of Psychosomatic Research, 33, 241-248.

Fishbach, A., \& Dhar, R. (2005). Goals as excuses or guides: the liberating effect of perceived goal progress on choice. Journal of Consumer Research, 32, 370-377.

Higgins, E. T., \& Trope, Y. (1990). Activity engagement theory: implications of multiply identifiable input for intrinsic motivation. In E. T. Higgins \& R. M. Sorrentino (Eds.), Handbook of motivation and cognition: Foundations of social behavior (Vol. 2, pp. 229-264). New York: Guilford Press.

Higgins, E. T., Lee, J. J., Kwon, J., \& Trope, Y. (1995). When combining intrinsic motivations undermines interest: a test of activity engagement theory. Journal of Personality and Social Psychology, 68, 749-767.

Karageorghis, C. I., \& Terry, P. C. (1997). The psychophysical effects of music in sport and exercise: a review. Journal of Sport Behavior, 20, 54.

Khan, U., \& Dhar, R. (2006). Licensing effect in consumer choice. Journal of Marketing Research, 43, 259-266.

King, N. A. (1999). What processes are involved in the appetite response to moderate increases in exerciseinduced energy expenditure? Proceedings of the Nutrition Society, 58, 107-113.

King, N. A., Snell, L., Smith, R. D., \& Blundell, J. E. (1996). Effects of short-term exercise on appetite responses in unrestrained females. European Journal of Clinical Nutrition, 50, 663-667.

Kivetz, R., \& Simonson, I. (2002). Earning the right to indulge: effort as a determinant of customer preferences toward frequency program rewards. Journal of Marketing Research, 39, 155-170.

Kivetz, R., \& Zheng, Y. (2006). Determinants of justification and self-control. Journal of Experimental Psychology: General, 135, 572-587.

Laran, J., \& Janiszewski, C. (2011). Work or fun? how task construal and completion influence regulatory behavior. Journal of Consumer Research, 37, 967-983.

Lerouge, D. (2009). Evaluating the benefits of distraction on product evaluations: the mind-set effect. Journal of Consumer Research, 36, 367-379.

Lichtman, S. W., Pisarska, K., Berman, E. R., Pestone, M., Dowling, H., Offenbacher, E., et al. (1992). Discrepancy between self-reported and actual caloric intake and exercise in obese subjects. New England Journal of Medicine, 327(27), 1893-1898. 
Martin, B. A. S., Veer, E., \& Pervan, S. J. (2007). Self-referencing and consumer evaluations of larger-sized female models: a weight locus of control perspective. Marketing Letters, 18, 197-209.

Martins, C., Morgan, L. M., Bloom, S. R., \& Robertson, M. D. (2007). Effects of exercise on gut peptides, energy intake and appetite. Journal of Endocrinology, 193, 251-258.

Mischel, W., Ebbesen, E. B., \& Zeiss, A. R. (1972). Cognitive and attentional mechanisms in delay of gratification. Journal of Personality and Social Psychology, 21, 204-218.

Mischel, W., Shoda, Y., \& Rodriguez, M. L. (1989). Delay of gratification in children. Science, 244, 933-938.

Mukhopadhyay, A., \& Johar, G. V. (2009). Indulgence as self-reward for prior shopping restraint: a justification-based mechanism. Journal of Consumer Psychology, 19(3), 334-345.

Nowlis, S. M., \& Shiv, B. (2005). The influence of consumer distractions on the effectiveness of foodsampling programs. Journal of Marketing Research, 42(2), 157-168.

Ryan, R. M., \& Deci, E. L. (2008). From ego depletion to vitality: theory and findings concerning the facilitation of energy available to the self. Social and Personality Psychology Compass, 2(2), 702-717.

Shiv, B., \& Nowlis, S. M. (2004). The effect of distractions while tasting a food sample: the interplay of informational and affective components in subsequent choice. Journal of Consumer Research, 31, 599608.

Strahilevitz, M., \& Myers, J. G. (1998). Donations to charity as purchase incentives: how well they work may depend on what you are trying to sell. Journal of Consumer Research, 24, 434-446.

Wansink, B., \& Chandon, P. (2006). Can 'low-fat' nutrition labels lead to obesity? Journal of Marketing Research, 43, 605-617.

Werle, C. O. C., Wansink, B., \& Payne, C. (2011). Just thinking about exercise makes me serve more food. Appetite, 56(2), 332-335.

Zhao, X., Lynch, J. G., Jr., \& Chen, Q. (2010). Reconsidering Baron and Kenny: myths and truths about mediation analysis. Journal of Consumer Research, 37(2), 197-206. 